\title{
A Seroepidemiological Survey of Hantavirus in Ilheus County
}

\author{
${ }^{1}$ Marcos Lazaro Moreli, ${ }^{1}$ Vivaldo Gomes da Costa and ${ }^{2}$ Flavia Rubia Pariz \\ ${ }^{1}$ Department of Biomedicine, Campus Jatai, Federal University of Goias, \\ Highway BR 364, Km 192, Industrial Park, 3.800, CEP: 75801-615, Jatai, Brazil \\ ${ }^{2}$ Department of Biological Sciences, Faculty of Biomedicine, State University of Santa Cruz, \\ Highway Ilheus/Itabuna BR 415, Km 16, CEP: 45662-000, Ilheus, Brazil
}

Received 2012-08-11, Revised 2012-08-29; Accepted 2012-08-29

\begin{abstract}
Hantaviral diseases are infections caused by a group of viruses that belong to the genus hantavirus and the family Bunyaviridae. In Brazil, several cases of hantavirus have been detected with the use of serological methods including immunofluorescence and Enzyme-Linked Immunosorbent Assay (ELISA). To date, 1.573 cases have been reported in several states across the country with a fatality rate of $41 \%$. No seroepidemiologic study has ever been conducted in the city of, or region surrounding, Ilheus, where large remnants of the Atlantic Forest provide shelter for a variety of rodents. The authors used the $\mathrm{N}$ recombinant protein of Araraquara virus as antigen to test for the presence of hantavirus-specific IgG antibodies by ELISA in samples provided by blood donors in the city of Ilheus, State of Bahia. The authors collected blood samples from 500 donors. Among these, $93.6 \%$ of the donors came from an urban area and $6.4 \%$ were from a rural area. A total of $0.6 \%$ of the donors was seropositive for anti-hantavirus IgG antibodies. This positivity was detected only in males at a rate of $1.1 \%$. However, there was no observed association for hantavirus seropositivity between the genders $(p=0.252)$. There was a higher frequency of seropositive individuals aged between 31 and 40 years $(1.6 \%)$, although the difference observed was not statistically significant $(\mathrm{p}=0.41)$. There was also a higher rate of seropositive individuals among donors from rural areas $(6.6 \%)$; the association for seropositivity between participants in rural and urban areas was statistically significant $(\mathrm{p}=0.011)$ by Fisher's exact test $(\mathrm{p}<0.05)$. The present study describes Araraquara virus circulation in this region for the first time. The results of this study provide the basis for future investigation of the hantaviruses that are associated with cardiopulmonary syndrome and the other antigenic ally related hantaviruses in this region.
\end{abstract}

Keywords: Hantavirus, Seroepidemiology, Araraquara Virus, Enzyme-Linked Immunosorbent Assay (ELISA)

\section{INTRODUCTION}

Viruses of the genus Hantavirus, which belongs to the family Bunyaviridae, are shelled viruses whose capsids are spherically symmetric with a diameter of 80 to $120 \mathrm{~nm}$. Their genome is composed of tri-segmented singlestranded Ribonucleic Acid (RNA) of negative polarity. The $\mathrm{S}$ ("small"), M ("medium") and L ("large") segments encode for the nucleocapsid's $\mathrm{N}$ protein, the envelope glycoproteins known as G1 and G2 or Gn and Gc and an RNA-dependent RNA polymerase, respectively
(Schmaljohn et al., 1986; Alfadhli et al., 2001). The viruses are distributed worldwide and are responsible for the following two distinct human diseases: Hemorrhagic Fever with Renal Failure Syndrome (HFRS) and Hantavirus Cardiopulmonary Syndrome (HCPS). Both of these diseases are acquired through the inhalation of aerosols originating from the excreta (urine, feces and saliva) of infected rodents (Lee and Vander, 1989; Schmaljohn and Hjelle, 1997; Avsic-Zupanc et al., 2000). Incidentally, research addressing the possibility of interhuman transmission has been published (Enria et al., 1996;

Corresponding Author: Marcos Lazaro Moreli, Department of Biomedicine, Campus Jatai, Federal University of Goias, Highway BR 364, Km 192, Industrial Park, 3.800, CEP: 75801-615, Jatai, Brazil 
Wells et al., 1997; Padula et al., 2000). Persons with HCPS experience an incubation period that ranges from 0 to 33 days, with an average of 15 days. Before the onset of pulmonary edema, are observed for 3 to 6 days viremia and early symptoms such as fever, myalgia, nausea, vomiting, diarrhea, cough, dyspnea and other less frequent prodromes. The disease then progresses to the cardiopulmonary phase where there is a progressive infiltration of fluid into the alveoli. The consequences of changes in vascular permeability are tachypnea, hypoxia and tachycardia. In the advanced stages of disease, hypotension can cause shock and death (Jenilson et al., 1995; Hallin et al., 1996; Young et al., 2000; SVS, 2005).

The laboratory diagnosis of hantavirus infection is mainly performed by Enzyme-Linked Immunosorbent Assay (ELISA), immunofluorescence antibody assay, or Reverse Transcription Polymerase Chain Reaction (RTPCR), with ELISA being the most common. The ELISA method that is performed is based on both a direct test for the detection of IgG antibodies and a capture test for the detection of $\operatorname{IgM}$ antibodies that interact with structural components of the virus from the serum of patients. To this end, viral protein preparations are obtained from cell cultures or heterologous expression systems. The improved detection of hantavirus infections is of singular importance for HCPS treatment because the period of infection that leads to death is relatively brief. In Brazil, the laboratory diagnoses of HCPS are conducted at the Instituto Adolfo Lutz (Sao Paulo), Instituto Evandro Chagas (Belem) and Fiocruz (Rio de Janeiro). The diagnosis is based on an Ig M Antibody Capture Enzyme-Linked Immunosorbent Assay (MAC-ELISA) and is performed with commercial kits that contain preparations of Andes virus recombinant protein from cell cultures. In Brazil, two proteins produced from the Araraquara and Araucaria (Juquitiba-like) circulating hantaviruses have been used in the diagnosis of hantavirus in several regions (Raboni et al., 2007; Figueiredo et al., 2009).

The authors highlight that the hantaviruses found in South America (Argentina, Bolivia, Brazil, Chile, Paraguay and Uruguay), which are related to rodents of the subfamily Sigmodontinae, form a group that is phylogenetically distinct from the North American hantavirus. Considering the complexity of the South American sigmodontine subfamily, which includes 61 genera and 299 species, systematic investigations for the detection and characterization of new hantaviruses becomes relevant. This is true not only with respect to the evolutionary study of the virus but also in particular with regard to improving the understanding of the epidemiology and the diagnosis of HCPS in South American countries. In Brazil, the authors characterized six different hantavirus strains: Juquitiba, Castelo dos Sonhos, Araraquara,
Anajatuba, Rio Mearim and Araucaria. There is currently no consensus on the establishment of viral species and the authors will be treating the Brazilian strains as hantavirus genotypes. The Juquitiba and Araraquara variants occur in the state of São Paulo (Engel et al., 1998; Johnson et al., 1999; Monroe et al., 1999; Bohlman et al., 2002; Moreli et al., 2004; Suzuki et al., 2004).

In addition, the Araraquara strain has also been described in the Brazilian Central Plateau, although the genetic characterization of the virus in this region is scarce. The Castelo dos Sonhos strain was isolated in the states of Mato Grosso and Pará, the Araucária strain was isolated in the state of Paraná and the Rio Mearim and Anajatuba strains were isolated in the state of Maranhao (Johnson et al., 1999; Bisordi et al., 2004; Raboni et al., 2005a; 2005b; Rosa et al., 2005; SVS, 2005). There is a broad occurrence of hantavirus infection in Brazil and the affected areas include the Federal District and the states of São Paulo, Minas Gerais, Goiás, Mato Grosso, Paraná, Santa Catarina, Rio Grande do Sul, Amazonas, Bahia, Pará and Rondônia.

Despite the growing number of cases in Brazil, studies similar to this one are still rare, especially in the Northeast region, where few cases have been detected. In particular, the State of Bahia is the site of only one published study that measured the prevalence of hantavirus infections caused by the Hantaan strain in specific populations of primary-school students in the city of Salvador (Mascarenhas-Batista et al., 1998). Research pertaining to the etiology and epidemiology of hantaviruses is still limited, especially in regions where isolated cases of the disease go undetected. This is possibly due to the nonspecific symptoms that are common to other diseases, the lack of continuity during a differential diagnosis (pre or post-mortem) and the lack of seroprevalence studies that indicate the virus circulation in various regions (Silva et al., 1997). For these important reasons, this study investigated the presence of hantavirus-reactive antibodies in blood donors in the city of Ilheus, Bahia using the $\mathrm{N}$ recombinant protein of the Araraquara virus (rN ARAV) as antigen.

\section{MATERIALS AND METHODS}

\subsection{Characterization of the Study Site}

This study aimed to access the prevalence of hantavirus-specific antibodies in blood samples isolated from donors in the municipality of Ilheus from June 2008 to December 2009. The research was developed in the Laboratory of Environmental Monitoring and Molecular Pharmacology and Epidemiology of State University of Santa Cruz (SUSC). The city of Ilheus is located in southern Bahia $\left(14^{\circ} \mathrm{C} 47^{\prime} 20^{\circ}\right.$ 'S, $39^{\circ} \mathrm{C} 2$ ' 56" W), which was formerly known as the cacao micro-region and is characterized by a humid tropical and sub-tropical climate 
with average temperatures ranging between $22^{\circ} \mathrm{C}$ and $28^{\circ} \mathrm{C}$ and an annual precipitation averaging $2.000 \mathrm{~mm}$. The municipality has an area of 1.847 square $\mathrm{km}$ and an estimated population of 184.231 inhabitants. It partially consists of remnants of the Atlantic Rainforest, which are possibly home to several species of wild rodents and other animals. The city's economy is based on industry, tourism and agriculture, a major component of which is the production of cocoa (IBGE, 2003).

\subsection{Control Antigens}

For the realization of the study, the authors were provided with a control group of positive (rN ARAV) and negative (protein extracts derived from Escherichia coli) antigens from Prof. Dr. Luiz Tadeu Moraes Figueiredo of the Centro de Pesquisa em Virologia (Center for Virology Research). He also donated a $100 \mu \mathrm{L}$ aliquot of positive control serum from a patient diagnosed with hantavirus (in the convalescence phase) from Ribeirão Preto.

\subsection{Ethical Issues}

Prior to the collection of clinical samples (sera), the study was presented to the ethics committee on human research of SUSC to ensure that it adequately approached patients and collected and presented the terms of free and informed consent to the patients. This study, entitled "A seroepidemiological survey for hantavirus in Ilheus, southern Bahia state", was approved at meeting number 72 on May 28, 2008 with the consolidated opinion number of 522.

\subsection{Sizing and Sample Collection}

The Haematology Service of the Santa Casa de Misericordia de Ilheus-Banco Sanguíneo (Ilheus' Blood Bank) collected the samples under the supervision of the coordinator Dr. Naide Silveira. Due to a limited availability of the $\mathrm{N}$ recombinant protein for the serosurvey, the sample size for this study was limited to 500 individuals who were residing in the different neighborhoods of Ilheus. After the donors agreed to participate in the study, $5 \mathrm{~mL}$ of blood was collected without regard to age, race and sex. Subsequently, $2 \mathrm{~mL}$ of serum (plasma) was obtained from each individual's sample. The sera were stored at $-20^{\circ} \mathrm{C}$ until they were sent to the Laboratory of Molecular Pharmacology and Epidemiology (SUSC), where the samples were processed for the ARAV-derived $\mathrm{N}$ recombinant protein-based ELISA (Figueiredo et al., 2009). The authors also collected sera from students and teachers at the SUSC to be used as negative controls during the testing.

\subsection{ELISA Using the $N$ Recombinant Protein of the ARAV}

The human sera retrieved from blood donors were subjected to ELISA for the detection of IgG antibodies, in accordance with the previously standardized procedure of Moreli (2005) and Figueiredo et al. (2009), at the Research Center of Virology at the School of Medicine of Ribeirão Preto, which is a part of the University of São Paulo.

First, 96-well microplates were coated with the $\mathrm{N}$ recombinant protein of the ARAV (wells: A-D, 1-12) and a negative antigen extract (E. coli; wells: E-H, 1-12), which were both diluted in Phosphate Buffered Saline (PBS) buffer, $\mathrm{pH}$ 9.6. The plates were incubated overnight at $4{ }^{\circ} \mathrm{C}$ in a moist chamber. On the next day, the microplates were washed five times with $0.05 \%$ Tween-20 in PBS (PBS-T), $\mathrm{pH}$ 7.4. A solution of $10 \%$ skim milk in PBS was added to the wells, which were then incubated for $1 \mathrm{~h}$ and washed six times. The microplates were incubated in humid chambers for $2 \mathrm{~h}$ at $37^{\circ} \mathrm{C}$ and then washed five times with PBS-T. The sera to be tested, as well as a positive IgG sera (positive control) and a pool of negative IgG sera (negative control), were added in triplicate to the corresponding wells at a 1:100 dilution in both sections of the plate. After a1 $\mathrm{h}$ incubation at $37^{\circ} \mathrm{C}$ in a humid chamber, the plates were washed six times with PBS-T. An immunoglobulin conjugate (goat anti-human IgG peroxidase) was diluted 1:2000 in PBS-T containing 10\% skimmed milk, added to the wells, incubated for $1 \mathrm{~h}$ and then washed six times. Subsequently, the ABTS substrate was added to the wells and incubated for $15-20 \mathrm{~min}$ at $37^{\circ} \mathrm{C}$ in a humid chamber for the development of color. The reaction was blocked with a $1 \mathrm{M} \mathrm{HCl}$ solution and the absorbance (Optical Density (OD)) was read in a spectrophotometer at $405 \mathrm{~nm}$. After subtracting the OD values of the wells that were coated with the negative extract from those that were coated with the $\mathrm{N}$ protein of ARAV, the cut-off point at each serum dilution was determined as the mean of the optical densities of the triplicate negative control sera plus three standard deviations. Serum tests were determined positive when their liquid ODs were higher than the value of the cut-off point (Moreli, 2005; Figueiredo et al., 2009).

\subsection{Data Analysis}

After obtaining the optical density of the serum samples from each blood donor by ELISA, the resulting data were associated with the demographic, professional and occupational information that appeared on the forms filled out by the donors. Moreover, as this was the first epidemiological study of the region, we chose to indiscriminately collect samples from this population that is predominantly urban. To evaluate the possible associations between the seropositivity and the variables assessed, we used the chi-squared and Fisher's exact tests and for both, the level of statistical significance was $5 \%(p \leq 0.05)$. 
Marcos Lazaro Moreli et al. / American Journal of Virology 1 (1): 18-23, 2012

Table 1. Seropositivity for hantavirus-specific antibodies in relation to the gender and age of the participants

\begin{tabular}{|c|c|c|c|c|c|c|c|c|c|}
\hline \multirow[b]{3}{*}{ Age range } & \multicolumn{9}{|c|}{ Gender } \\
\hline & \multicolumn{3}{|c|}{ Masculine } & \multicolumn{3}{|c|}{ Feminine } & \multicolumn{3}{|c|}{ Total } \\
\hline & $\operatorname{Pos}^{a}$ & Total & $(\%)$ & Pos & Total & $(\%)$ & Pos & Total & $(\%)$ \\
\hline$\overline{15-20}$ & 0 & 41 & 0.0 & 0 & 40 & 0 & 0 & 81 & 0.0 \\
\hline $21-30$ & 1 & 64 & 1.6 & 0 & 61 & 0 & 1 & 125 & 0.8 \\
\hline $31-40$ & 2 & 70 & 2.8 & 0 & 50 & 0 & 2 & 120 & 1.6 \\
\hline $41-50$ & 0 & 56 & 0.0 & 0 & 56 & 0 & 0 & 112 & 0.0 \\
\hline $51-60$ & 0 & 35 & 0.0 & 0 & 27 & 0 & 0 & 620 & 0.0 \\
\hline Total & 3 & 266 & 1.1 & 0 & 234 & 0 & 0 & 500 & 0.6 \\
\hline
\end{tabular}

Table 2. Data from the donors seropositive for protein rN ARAV

\begin{tabular}{llllll}
\hline Sex & Age & Profession & $\begin{array}{l}\text { Place of } \\
\text { activity }\end{array}$ & $\begin{array}{l}\text { Positivity } \\
(\%)\end{array}$ & $\begin{array}{l}\text { Level of } \\
\text { absorbance }\end{array}$ \\
\hline Masculine & 33 & Policeman & Urban & 0.22 & 0.301 \\
Masculine & 37 & Cocoa grower & Rural & & 0.404 \\
Masculine & 26 & Driver & Rural & 6.6 & 0.601 \\
\hline
\end{tabular}

${ }^{\mathrm{b}}$; The cutoff value was 0.184

\section{RESULTS}

The serosurvey consisted of 500 blood donors living in the city of Ilheus. The data collected from the participants regarding their gender, age range and presence of $\mathrm{IgG}$ antibodies against ARAV are presented in Table 1. Three individuals, all of whom were masculine, had antibodies that bound the rN ARAV protein. Therefore, a general positivity of $0.6 \%$ was observed and all of the positive individuals, as well as the negative cases, were autochthonous. A majority of the participants included in this study (54\%) were men, $1.1 \%$ of which were seropositive. Despite all of the positive cases being detected in males, the association between gender and seropositivity for hantavirus was not considered statistically significant by Fisher's exact test $(\mathrm{p}=0.252)$. Moreover, the minimum and maximum ages of the participants were 15 and 60 years, respectively, with a mean age of 35 years. The group that included individuals aged between 31 and 40 years had the highest frequency of seropositivity $(1.6 \%)$; however, there was no significant association between the participants' age and the prevalence of hantavirus-specific antibodies by the chi-squared test $(p=0.41)$.

Regarding the environment of the individuals, 442 were residents of urban areas, 30 were from rural areas and 28 did not provide this information. The main professional activities in the urban area were as follows: 221 were merchants, 100 were homemakers, 40 were students, 12 were cashiers, 10 were civil servants and 7 were businessmen. Among the rural participants, we found that 20 were cocoa farmers, 7 were farmers, 2 were drivers, 1 was an agronomist and 28 had an unknown or other professional activity, including 10 who were unemployed and 12 who were autonomous. Additionally, we observed that participants who had a rural place of activity showed a higher anti-hantavirus IgG positivity rate $(6.6 \%)$ than those from the urban area $(0.22 \%)$, as shown in Table 2 . The association between the seropositivity of participants in the rural and urban areas was statistically significant by Fisher's exact test $(p=0.011)$. None of the participants reported having had direct contact with wild rodents or their excreta products, such as urine and/or feces.

\section{DISCUSSION}

The present study demonstrated a $0.6 \%$ prevalence of antibodies against a hantavirus that is associated with HCPS in blood donors living in the city of Ilheus, which indiscriminately allowed us to know the level of hantavirus contact in this population. The clinical history of the positive participants did not appear to be compatible with hantavirus infection, whose diagnosis can be compromised in these situations because the patients are often asymptomatic or oligosymptomatic. Furthermore, the possibility of a false positive serology measurement in this study is remote because the ELISA uses a recombinant native protein that is highly specific and has been used frequently in various regions for serological screening, including South American countries such as Argentina (Bohlman et al., 2002). Figueiredo et al. (2009) tested the recombinant protein by ELISA for IgM and IgG antibodies in serum samples from patients known to be positive for hantavirus and obtained a sensitivity of $97.2 \%$, a specificity of $100 \%$ and a positive predictive value of $100 \%$.

In Brazilian epidemiological studies, the ARAV strain was detected in the rodent reservoir Necromys lasiurus, which inhabits a Brazilian ecosystem known as a cerrado. However, our study region is comprised of remnants of the Atlantic Forest biome, which is a primary habitat for the rodent Oligoryzomys nigripes, the natural reservoir for the Juquitiba virus strain. Both of these strains are human hantaviruses that are associated with HCPS within the Brazilian territory (Suzuki et al., 2004). However, because of the phylogenetic proximity of these two hantaviruses, a possible cross-reaction between the two strains cannot be 
ruled out. Similarly, research has noted a cross-reaction between the Andes virus (which is prevalent in parts of Argentina) and the protein substrate rN ARAV (Figueiredo et al., 2009). However, this fact is not a disadvantage of the methodology because what is most important is the early diagnosis of hantavirus because the late detection may contribute to the high fatality rate observed $(40 \%)$. Moreover, there is no specific treatment and only palliative procedures such as water control, mechanical ventilation and administration of vasoactive drugs are enacted.

The $0.6 \%$ seroprevalence of antibodies against hantavirus detected by us is similar to the serological survey conducted by Gimaque et al. (2012) that used the same technique and found an $\mathrm{IgG}$ seropositivity of $0.6 \%$ in samples from the urban and rural areas of four municipalities in the State of Amazon. Another study, conducted in cities in the State of Santa Catarina near the border between Brazil and Argentina (Souza et al., 2011), found a much higher seropositivity (3.5\%) for IgG antibodies to hantavirus compared with our study; however, most of the HCPS have occurred in this country's southern and southeast regions. Additionally, a retrospective research of hantavirus infection that was performed slightly closer to our region, in the city of Cássia dos Coqueiros, State of Sao Paulo, found positive results in $4.7 \%$ of the samples (Badra et al., 2012). Lastly, in another South American study in Chile, the researchers found a similar seroprevalence $(0.72 \%)$ of antibodies to the Andes virus (Frey et al., 2003).

The statistical analysis of seropositivity showed that the only significant association was whether the participants were from rural and urban areas. Of the positive samples, $66 \%$ came from the rural areas and $33 \%$ were urban. In the study by Gimaque et al. (2012), the frequency of the hantavirus-specific $\operatorname{IgG}$ antibody positive samples in the rural and urban areas was $80 \%$ and $20 \%$, respectively. Although hantavirus is known to primarily be a rural disease, the selection of participants for epidemiological studies should also include people from the urban area, as many city dwellers have small farms and perform agricultural activities, which increases the possibility of contact with wild rodents or their excreta. Moreover, the inhabitants of peri-urban neighborhoods who are close to forests, pastures or agricultural areas, as well as people who live and work in central urban areas and have access to farms for leisure activities, especially during weekends, are all susceptible to a greater risk of exposure (Badra et al., 2012).

Previous studies in the State of Bahia did not show the presence of HCPS-associated anti-hantavirus antibodies in children but did show the presence of antibodies to Sin Nombre in adults $(0.2 \%)$ and antibodies to Hantaan (27.2\%) (Mascarenhas-Batista et al., 1998). Nevertheless, we emphasize that false positives can occur in these studies using the immunofluorescence technique due to the use of imported antigens related to Sin Nombre and Hantaan virus, whereas the use of a native protein (rN ARAV) is more likely antigenic ally related to the hantaviruses circulating in Brazil.

\section{CONCLUSION}

The present study is the first demonstration in this region of the presence of $\mathrm{IgG}$ antibodies that bind to the $\mathrm{N}$ recombinant protein of Araraquara virus in $0.6 \%$ of blood samples from donors in the city of Ilheus. The results of this study provide the basis for future investigation of the hantaviruses that are associated with HCPS and the other antigenic ally related hantaviruses in this region. Molecular biology methods, such as RT-PCR with specific primers, could be utilized on clinical samples from patients suspected of acute phase infections to identify the circulating viruses and the rodent reservoirs.

\section{ACKNOWLEDGMENT}

This study was partially funded by a research grant from the Conselho Nacional de Desenvolvimento Científico e Tecnológico-CNPq (Grant 486245/2007-1).

\section{COMPETING INTERESTS}

The Researchers declare that they have no competing interests.

\section{REFERENCES}

Alfadhli, A., Z. Love, B. Arvidson, J. Seeds and J. Willey et al., 2001. Hantavirus nucleocapsid protein oligomerization. J. Virol., 75: 2019-2023. DOI: 10.1128/JVI.75.4.2019-2023.2001

Avsic-Zupanc, T., K. Nemirov, M. Petrovec, T. Trilar and M. Poljak et al., 2000. Genetic analysis of wild-type dobrava hantavirus in Slovenia: Co- existence of two distinct genetic lineages within the same natural focus. J. Gen. Virol., 81: 1747-1755.

Badra, S.J., F.G.M. Maia, G.G. Figueiredo, G.S.S. Junior and G.M. Campos et al., 2012. A restropective serologic survey of hantavirus infections in the county of Cassia dos Coqueiros, State of Sao Paulo, Brazil. Rev. Soc. Bras. Med. Trop.

Bisordi, I., A. Suzuki, S. Levis, J. Garcia and L.E. Pereira et al., 2004. Identifying rodent hantavirus reservoirs, Brazil. Emerg. Infect. Dis., 10: 2127-2134.

Bohlman, M.C., S.P. Morzunov, J. Meissner, M.B. Taylor and K. Ishibashi et al., 2002. Analysis of hantavirus genetic diversity in argentina: $\mathrm{S}$ segment-derived phylogeny. J. Virol., 76: 3765-3773. DOI: 10.1128/JVI.76.8.3765-3773.2002 
Engel, S.R., K.M. Hogan, J.F. Taylor, S.K and Davis SK, 1998. Molecular systematics and paleobiogeography of the South American sigmodontinae rodents. Mol. Biol. Evol., 15: 35-49.

Enria, D.A., P.J. Padula and E.L. Segura, 1996. Hantavirus pulmonary syndrome in argentina: Possibility of person to person transmission. Med. (B. Aires), 56: 709-711.

Figueiredo, L.T.M., M.L. Moreli, A.A. Borges, G.G. Figueiredo and S.J. Badras et al., 2009. Evaluation of an enzyme-linked immunosorbent assay based on araraquara virus recombinant nucleocapsid protein. Am. J. Trop. Med. Hyg., 81: 273-276.

Frey, M.T., P.C. Vial, C.H. Castillo, P.M. Godoy and B. Hjelle et al., 2003. Hantavirus prevalence in the IX Region of Chile. Emerg. Infect. Dis., 9: 827-832.

Gimaque, J.B.L., M.S. Bastos, W.S.M. Braga, C.M.C. Oliveira and M.C. Castilho et al., 2012. Serological evidence of hantavirus infection in rural and urban regions in the state of Amazonas, Brazil. Mem. Inst. Oswaldo Cruz, 107: 135-137.

Hallin, G.W., S.Q. Simpson, R.E. Crowell, D.S. James and F.T. Koster et al., 1996. Cardiopulmonary manifestations of hantavirus pulmonary syndrome. Crit. Care Med., 24: 252-258.

IBGE, 2003. Instituto Brasileiro de Geografia e Estatistica. IBGA.

Jenilson, S., B. Hjelle, S. Simpson, G. Hallin, R. Feddersen and F. Koster, 1995. Hantavirus pulmonary syndrome: clinical, diagnostic and virologic aspects. Semin. Respir. Infect., 10: 259-269.

Johnson, A.M., L.T.D. Souza, I.B. Ferreira, L.E. Pereira and T.G. Ksiazek et al., 1999. Genetic investigation of novel hantaviruses causing fatal HPS in Brazil. J. Med. Virol., 59: 527-535. DOI: 10.1002/(SICI)10969071(199912)59:4<527::AID-JMV17>3.0.CO;2-Y

Lee, H.W. and G.G. Vander, 1989. Hemorrhagic fever with renal syndrome. Prog. Med. Virol., 36: 62-102. PMID: 2573914

Mascarenhas-Batista, A.V., E.S. Da Rosa, T.G. Ksiazek, A.P. Da Rosa and J.W. Leduc et al., 1998. AntiHantavirus antibodies in school children in Salvador, Bahia. Rev. Soc. Bras. Med. Trop., 31: 433-440.

Monroe, M.C., S.P. Morzunov, A.M. Johnson, M.D. Bowen and H. Artsob et al., 1999. Genetic diversity and distribution of Peromyscus-borne hantaviruses in North America. Emerg. Infect. Dis., 5: 75-86.

Moreli, M.L., 2005. Diagnosis by detection of hantavirus genomic and phylogenetic analysis with a recombinant protein production. University of Sao Paulo, Brazil.

Moreli, M.L., R.L. Souza and L.T. Figueiredo, 2004. Detection of Brazilian hantavirus by reverse transcription polymerase chain reaction amplification of $\mathrm{N}$ gene in patients with hantavirus cardiopulmonary syndrome. Mem. Inst. Oswaldo Cruz, 99: 633-638.
Padula, P.J., S.B. Colavecchia, V.P. Martinez, D.V Gonzalez and A. Edelstein et al., 2000. Genetic diversity, distribution and serological features of hantavirus infection in five countries in South America. J. Clin. Microbiol., 38: 3029-3035.

Raboni, S.M., G. Rubio, L. De Borba, A. Zeferino and I. Skraba et al., 2005b. Clinical survey of hantavirus in southern Brazil and the development of specific molecular diagnosis tools. Am. J. Trop. Med. Hyg., 72: 800-804.

Raboni, S.M., M. Probst, J. Bordignon, A. Zeferino and C.N.D. Santos, 2005a. Hantaviruses in Central South America: Phylogenetic analysis of the S segment from HPS cases in Parana, Brazil. J. Med. Virol., 76: 553562. DOI: $10.1002 /$ jmv.20398

Raboni, S.M., S. Levis, E.S. Rosa, I. Bisordi and A. Delfraro et al., 2007. Hantavirus infection in Brazil: Development and evaluation of an enzyme immunoassay and immunoblotting based on $\mathrm{N}$ recombinant protein. Diag. Microbiol. Infect. Dis., 58: 89-97. DOI: 10.1016/j.diagmicrobio.2006.11.012

Rosa, E.S., J.N. Mills, P.J. Padula, T.G. Ksiazek and W.S. Mendes et al., 2005. Newly recognized hantaviruses associated with hantavirus pulmonary syndrome in northern Brazil: Partial genetic characterization of viruses and serologic implication of likely reservoirs. VectorBorne Zoonotic. Dis., 5: 11-19.

Schmaljohn, C. and B. Hjelle, 1997. Hantaviruses: A global disease problem. Emerg. Infect. Dis., 3: 95-104.

Schmaljohn, C.S., G.B. Jennings, J. Hay and J.M. Dalrymple, 1986. Coding strategy of the S genome segment of hantaan virus. Virology, 155: 633-643.

Silva, M.V.D., M.J. Vasconcelos, N.T. Hidalgo, M. Veiga and P.C. Canzian et al., 1997. Hantavirus pulmonary syndrome. Report of the first three cases in Sao Paulo, Brazil. Rev. Inst. Med. Tropical Sao Paulo, 39: 231234. DOI: 10.1590/S0036-46651997000400010

Souza, W.M., A.M. Machado, L.T.M. Figueiredo and E. Boff, 2011. Serosurvey of hantavirus infection in humans in the border region between Brazil and Argentina. Rev. Soc. Bras. Med. Trop., 44: 131-135.

Suzuki, A., I. Bisordi, S. Levis, J. Garcia, L.E. Pereira and R.P. Souza et al., 2004. Identifying rodent hantavirus reservoirs, Brazil. Emerg. Infect. Dis., 410: 2127-2134.

SVS, 2005. Secretaria de Vigilancia em Saude. SVS.

Wells, R.M., E.S. Sosa, Z.E. Yadon, D. Enria and P. Padula et al., 1997. An unusual hantavirus outbreak in southern Argentina: Person-to-person transmission? Hantavirus pulmonary syndrome study group for patagonia. Emerg. Infect. Dis., 3: 171-174.

Young, J.C., G.R. Hansen, T.K. Graves, M.P. Deasy and J.G. Humphreys et al., 2000. The incubation period of hantavirus pulmonary syndrome. Am. J. Trop. Med. Hyg., 62: 714-717. 